\title{
Fiscal Policy and Business Formation in Open ECONOMIES
}

\author{
Vivien Lewis* \\ KU Leuven $\& 3$ Deutsche Bundesbank
}

\author{
Roland Winkler ${ }^{\dagger}$ \\ TU Dortmund University
}

August 10, 2015

\begin{abstract}
According to empirical evidence, expansionary government spending policies increase consumption and the number of active firms in an economy and have large positive international spillover effects. Using a two-country sticky-price model with a variable number of producers, we analyze movements in output, consumption, extensive-margin investment and foreign output in response to government spending expansions. Our baseline results show that, first, there is divergence between consumption and firm entry; and second, spillovers are generally small. A large share of imports in government spending or a high trade elasticity can generate large spillovers in the model, but do not induce consumption-investment comovement. We propose useful government spending as a device to induce both large spillovers and positive consumption-investment comovement.
\end{abstract}

JEL classification: E62, F42.

Keywords: consumption-investment comovement, firm entry, government spending, international spillovers.

${ }^{*}$ KU Leuven, Center for Economic Studies, Naamsestraat 69, 3000 Leuven, Belgium, tel. +32 16373732, vivien.lewis@kuleuven.be, http://sites.google.com/site/vivienjlewis.

${ }^{\dagger}$ TU Dortmund University, Faculty of Business, Economics, and Social Sciences, Vogelpothsweg 87, 44221 Dortmund, Germany, roland.winkler@tu-dortmund.de, http://sites.google.com/site/rolandcwinkler. 


\section{Introduction}

Large fiscal spending programs, enacted in Europe and the US in response to the global economic crisis, have stimulated interest in the international transmission of government spending expansions. If expansionary policies have beggar-thy-neighbor effects, an individual country's efforts to boost economic activity could have adverse consequences for its trading partners. Since the ongoing crisis has hit countries on a global scale, understanding the international effects of policies is more important than ever.

The textbook Mundell-Fleming model makes two stark predictions regarding cross-country spillovers. First, increases in government spending have positive short run effects on output in the country's trading partners. Second, the country's real exchange rate appreciates. Empirical evidence by Canzoneri et al. (2003) confirms these predictions. Regarding the home country effects, empirical evidence suggests that government spending expansions stimulate private consumption and extensive-margin investment, i.e. firm entry, see Lewis and Winkler (2015). Open economy models struggle to explain the rise in private economic activity in the domestic country together with sizable positive output spillovers and a real exchange rate appreciation after domestic government spending expansions. Corsetti et al. (2010) propose a two-country model in which a domestic spending expansion that comes along with the announcement of future government spending contractions leads to a positive comovement of domestic consumption and investment (at the intensive margin) and positive output spillovers on the foreign economy. However, in their model the domestic currency depreciates, which stands in contrast to recent evidence provided by Auerbach and Gorodnichenko (2015) who show that US government spending shocks lead to an appreciation of the US dollar.

We revisit the question of international fiscal policy spillovers using a business cycle model with endogenous producer entry (extensive margin investment) as in Bilbiie et al. (2012). More specifically, we extend the sticky-price version, Bilbiie et al. (2008), to an open economy setting. We propose a model where government spending and private consumption fall disproportionately on home-produced goods, as in Corsetti et al. (2010). Also, capital goods that new firms need to purchase to enter the domestic market are aggregates of home-produced and imported varieties, 
and their import content can differ from the consumption bundles of home households and the government. Cavallari (2013) shows that introducing endogenous firm entry, combined with entry costs with a substantial import content, into a two-country model helps to generate international output comovement in response to technology shocks as observed in the data.

Our results show that output spillovers are positive but rather small in the baseline model, while Canzoneri et al. (2003) find sizable spillovers in the data. A sensitivity analysis reveals that spillovers increase if the government buys a large share of goods abroad, or if the trade elasticity is very high. Both assumptions seem empirically implausible. We instead propose to include public goods in the model, modeled as government consumption entering household utility. We show that this model feature can generate positive and large international spillovers and a real appreciation of the home currency. In addition, consumption and firm entry positively comove with domestic government spending.

Sizeable cross-country spillovers of fiscal expansions have been empirically documented by, e.g., Canzoneri et al. (2005), Beetsma et al. (2006), and Auerbach and Gorodnichenko (2012). Corsetti et al. (2010) use, as we do, a two-country DSGE model to analyze the spillover effects of a unilateral government spending expansion. As mentioned above, their model produces sizeable output spillovers and a positive consumption-investment comovement in the home country if a rise in government spending today is accompanied by an announcement of future spending contractions (a spending reversal). Our paper is different from the paper by Corsetti et al. (2010) in that investment in our paper takes the form of creation of new firms instead of investment in physical capital. Firm entry has shown to be an important margin of investment altering the transmission of shocks to the economy, see e.g. Lewis and Stevens (2015). Moreover, we do not consider spending reversals here but instead propose useful government spending as an alternative modeling device to reconcile the model with the data. Spending reversals imply a depreciation of the domestic currency, whereas under useful government spending the domestic exchange rate robustly appreciates. The jury is still out on the effects of spending shocks on the real exchange rate. Some papers find evidence for a real exchange rate depreciation, e.g., Enders et al. (2011), Monacelli and Perotti (2010), and Ravn et al. (2012), while there is competing evidence of appreciations after spending 
shocks, see e.g., Auerbach and Gorodnichenko (2015), Canzoneri et al. (2005), Benetrix and Lane (2013), and Born et al. (2013).

The paper is structured as follows. Section 2 derives the two-country model featuring endogenous firm entry and strategic complementarities between producers. Thereafter in Section 3, we calibrate the model and show impulse responses to government spending expansions, both homecountry effects and cross-border spillovers. Section 4 explores the importance of parameter values in shaping model predictions. In Section 5, we extend the model to include useful government spending. Section 6 concludes.

\section{Model}

The model economy is composed of two countries, Home and Foreign (denoted $H$ and $F$ for short). The structure of the model is similar to Benigno and De Paoli (2010), where the two countries may differ in size. This allows us to consider the small open economy as a limiting case, where the size of the home country is shrunk to zero. Final goods firms in each country produce a homogeneous good consumed by home and foreign households, the home and foreign governments, and entrants in both countries. Each household consumes both home final goods and imports, but has a bias for goods produced domestically. In what follows, we use stars to indicate foreign variables and omit detailed derivations for the foreign economy wherever they are equivalent to those of the home country. ${ }^{1}$

\subsection{Production}

Within a country, we assume a two-layer production structure as in Devereux and Lee (2001) and Jaimovich and Floetotto (2008). In each country there exists a large number of differentiated industries. These are indexed by $i \in(0, n)$ in the home country, where $n \in(0,1)$ is the size of country $H$ relative to the rest of the world. In country $F$, industries are indexed by $i^{*} \in(n, 1)$, such that the size of the world is normalized to unity. Within each industry in country $H$, there is oligopolistic competition between a small and variable number of firms, indexed by $j=1, \ldots, N_{t}$.

\footnotetext{
${ }^{1} \mathrm{~A}$ detailed derivation of all model equations for the foreign economy can be found in the Appendix.
} 
Final Goods. The production function of the home-produced final good $Y_{H, t}$ is

$$
Y_{H, t}=\left[\left(\frac{1}{n}\right)^{\frac{1}{\theta_{i}}} \int_{0}^{n} y_{H, t}(i)^{\frac{\theta_{i}-1}{\theta_{i}}} d i\right]^{\frac{\theta_{i}}{\theta_{i}-1}}
$$

where $y_{H, t}(i)$ denotes the output of industry $i$ and $\theta_{i}$ denotes the elasticity of substitution between industry goods. A final goods firm bundles the differentiated industry goods $y_{H, t}(i)$, taking as given their price $P_{H, t}(i)$, and sells the output $Y_{H, t}$ at the competitive price $P_{H, t}$. The optimization problem of the final goods firm is to choose the amount of inputs that maximize profits, i.e. it solves:

$$
\max _{y_{H, t}(i), i \in(0, n)}\left\{P_{H, t} Y_{H, t}-\int_{0}^{n} P_{H, t}(i) y_{H, t}(i) d i\right\},
$$

subject to the production function (1). The first order condition gives the following demand for industry goods:

$$
y_{H, t}(i)=\frac{1}{n}\left(\frac{P_{H, t}(i)}{P_{H, t}}\right)^{-\theta_{i}} Y_{H, t} .
$$

Substituting $y_{H, t}(i)$ in the production function using (3) yields the aggregate price index:

$$
P_{H, t}=\left[\left(\frac{1}{n}\right) \int_{0}^{n} P_{H, t}(i)^{1-\theta_{i}} d i\right]^{\frac{1}{1-\theta_{i}}} .
$$

In an equilibrium where all industries are the same, the industry price and the price index coincide,

$$
P_{H, t}=P_{H, t}(i)
$$

Industry Goods. Differentiated intermediate goods are aggregated into an industry good according to the optimization problem:

$$
\max _{y_{H, t}(i, f)}\left\{P_{H, t}(i) y_{H, t}(i)-\sum_{j=1}^{N_{t}(i)} P_{H, t}(i, j) y_{H, t}(i, j)\right\},
$$

subject to the production function:

$$
y_{H, t}(i)=\left[\left(\frac{1}{n}\right)^{\frac{1}{\theta_{j}}} \sum_{j=1}^{N_{t}(i)} y_{H, t}(i, j)^{\frac{\theta_{j}-1}{\theta_{j}}}\right]^{\frac{\theta_{j}}{\theta_{j}-1}},
$$

where $y_{H, t}(i, j)$ is the output of firm $j$ in industry $i$ and $\theta_{j}$ denotes the elasticity of substitution between goods within an industry. Note that the production function of industry goods is specified 
such that there is no love of variety. ${ }^{2}$

The first order condition gives the following demand function for intermediate goods:

$$
y_{H, t}(i, j)=\frac{1}{N_{t}(i)}\left(\frac{P_{H, t}(i, j)}{P_{H, t}(i)}\right)^{-\theta_{j}} y_{H, t}(i) .
$$

Replacing industry output $y_{H, t}(i)$ using (3), we can also express this as:

$$
y_{H, t}(i, j)=\frac{1}{n N_{t}(i)}\left(\frac{P_{H, t}(i, j)}{P_{H, t}(i)}\right)^{-\theta_{j}}\left(\frac{P_{H, t}(i)}{P_{H, t}}\right)^{-\theta_{i}} Y_{H, t} .
$$

Substituting out $y_{H, t}(i, j)$ in the production function (6) using (7) yields the industry price index:

$$
P_{H, t}(i)=\left[\left(\frac{1}{n}\right) \sum_{j=1}^{N_{t}(i)} P_{H, t}(i, j)^{1-\theta_{j}}\right]^{\frac{1}{1-\theta_{j}}} .
$$

Intermediate Goods. Each intermediate goods firm $j$ in industry $i$ produces a single goods variety under a production technology that is linear in labor,

$$
y_{H, t}(i, j)=A_{t} l_{H, t}(i, j)
$$

where $A_{t}$ is an economy-wide technology index. Real profits per firm are therefore

$$
d_{t}(i, j)=\frac{P_{H, t}(i, j)}{P_{t}} y_{H, t}(i, j)-w_{t} l_{H, t}(i, j)-\frac{\kappa}{2}\left(\frac{P_{H, t}(i, j)}{P_{H, t-1}(i, j)}-1\right)^{2} \frac{P_{H, t}(i, j)}{P_{t}} y_{H, t}(i, j),
$$

where $P_{H, t}(i, f) / P_{t}$ is the price of variety $j$ in industry $i$ relative to the final goods price $P_{t}$ and the last term in (11) are price adjustment costs. The firm takes marginal costs $w_{t} / A_{t}$ as given. Under Bertrand competition, intermediate goods firms set prices to maximize profits. Each firm takes into account how its price setting affects its own industry's price, while taking as given the prices chosen by other firms in the industry and the price levels of other industries.

The profit maximization problem of the representative firm producing variety $(i, j)$ becomes

$$
\max _{\left\{P_{H, t}(i, j)\right\}_{t=0}^{\infty}} E_{0} \sum_{t=0}^{\infty} \Lambda_{0, t}\left[\frac{P_{H, t}(i, j)}{P_{t}}-\frac{w_{t}}{A_{t}}-\frac{\kappa}{2}\left(\frac{P_{H, t}(i, j)}{P_{H, t-1}(i, j)}-1\right)^{2} \frac{P_{H, t}(i, j)}{P_{t}}\right] y_{H, t}(i, j),
$$

\footnotetext{
${ }^{2}$ Love of variety implies that utility is increasing in the number of goods varieties, even if the total amount consumed is held fixed. With this model feature, the price level is decreasing in the number of available varieties.
} 
subject to the demand constraint (8). The first order condition for prices is

$$
0=\frac{w_{t}}{A_{t}} \frac{P_{t}}{P_{H, t}(i, j)} \varepsilon_{y, P}-\left(\varepsilon_{y, P}-1\right)\left[1-\frac{\kappa}{2}\left(\frac{P_{H, t}(i, j)}{P_{H, t-1}(i, j)}-1\right)^{2}\right]-\kappa \Upsilon_{t}
$$

where

$$
\begin{aligned}
\Upsilon_{t}= & \frac{P_{H, t}(i, j)}{P_{H, t-1}(i, j)}\left(\frac{P_{H, t}(i, j)}{P_{H, t-1}(i, j)}-1\right) \\
& -E_{t}\left\{\Lambda_{t, t+1} \frac{y_{H, t+1}(i, j)}{y_{H, t}(i, j)} \frac{P_{t}}{P_{t+1}}\left(\frac{P_{H, t+1}(i, j)}{P_{H, t}(i, j)}\right)^{2}\left(\frac{P_{H, t+1}(i, j)}{P_{H, t}(i, j)}-1\right)\right\} .
\end{aligned}
$$

and the price elasticity of firms' demand in absolute value, $\varepsilon_{y, P}(i, j)=-\frac{\partial y_{H, t}(i, j)}{\partial P_{H, t}(i, j)} \frac{P_{H, t}(i, j)}{y_{H, t}(i, j)}$, is given by

$$
\varepsilon_{y, P}(i, j)=\theta_{j}+\left(\theta_{i}-\theta_{j}\right) \frac{P_{H, t}(i, j)^{1-\theta_{j}}}{\sum_{j=1}^{N_{t}(i)} P_{H, t}(i, j)^{1-\theta_{j}}} .
$$

Symmetric equilibrium. In a symmetric equilibrium, $P_{H, t}(i, j)=P_{H, t}(i)=P_{H, t}, N_{t}(i)=N_{t}$, industry output is firm output multiplied by the number of firms, $y_{H, t}(i)=y_{H, t}=N_{t} y_{H, t}(i, j)$, aggregate output is industry output multiplied by the mass of industries, $Y_{H, t}=n y_{H, t}$, and the total mass of firms in the home country is $n N_{t}$. Labor demand of industry $i$ is given by $l_{H, t}=$ $l_{H, t}(i)=N_{t} l_{H, t}(i, j)$ and total labor demand over all industries is $n l_{H, t}$.

The symmetric price setting condition in country $H$ is

$$
\begin{aligned}
\pi_{H, t}\left(\pi_{H, t}-1\right)= & \frac{\varepsilon_{t}}{\kappa}\left(\frac{P_{t}}{P_{H, t}} \frac{w_{t}}{A_{t}}-\frac{1}{\mu_{t}^{d}}\left[1-\frac{\kappa}{2}\left(\pi_{H, t}-1\right)^{2}\right]\right) \\
& +E_{t}\left\{\Lambda_{t, t+1} \pi_{H, t+1}\left(\pi_{H, t+1}-1\right) \frac{\pi_{H, t+1}}{\pi_{t+1}} \frac{y_{H, t+1}}{y_{H, t}} \frac{N_{t}}{N_{t+1}}\right\},
\end{aligned}
$$

where $\mu_{t}^{d}=\varepsilon_{t} /\left(\varepsilon_{t}-1\right)$ is the desired markup, the price-elasticity of demand is given by $\varepsilon_{t}=$ $\theta_{j}-\left(\theta_{j}-\theta_{i}\right) \frac{1}{N_{t}}, \pi_{H, t}=\frac{P_{H, t}}{P_{H, t-1}}$ is the change in the price of home-produced final goods (or home producer price inflation), and $\pi_{t}=\frac{P_{t}}{P_{t-1}}$ is consumer price inflation (CPI inflation). The desired markup,

$$
\mu_{t}^{d}=\frac{\theta_{j} N_{t}-\left(\theta_{j}-\theta_{i}\right)}{\left(\theta_{j}-1\right) N_{t}-\left(\theta_{j}-\theta_{i}\right)}
$$

varies negatively with the number of producers for $\theta_{j}>\theta_{i}$. If the between- and within-industry substitution elasticities are equal, $\theta_{j}=\theta_{i}$, the negative effect of entry on markups under Bertrand competition disappears and we revert to the constant elasticity of substitution (CES) structure à 
la Dixit and Stiglitz (1977). Broda and Weinstein (2006) estimate substitution elasticities between goods for different levels of aggregation. As they disaggregate product categories, goods varieties appear to be more substitutable to each other. This suggests that $\theta_{j}>\theta_{i}$ is a reasonable assumption and we will make this assumption throughout the remainder of the paper.

\subsection{Entry}

The existence of profits in excess of entry costs leads to market entry by firms. Every period, there exist $N_{t}$ intermediate goods firms within an industry $i$ and an infinite mass of potential entrants in the home country. Setting up a new firm in industry $i$ requires purchasing $f_{t}$ units of a composite good comprising home goods, $f_{H, t}$, and foreign goods, $f_{F, t}$,

$$
f_{t}=\left[\nu_{f}^{\frac{1}{\sigma}}\left(f_{H, t}\right)^{\frac{\sigma-1}{\sigma}}+\left(1-\nu_{f}\right)^{\frac{1}{\sigma}}\left(f_{F, t}\right)^{\frac{\sigma-1}{\sigma}}\right]^{\frac{\sigma}{\sigma-1}},
$$

which costs

$$
P_{f, t}=\left[\nu_{f}\left(P_{H, t}\right)^{1-\sigma}+\left(1-\nu_{f}\right)\left(P_{F, t}\right)^{1-\sigma}\right]^{\frac{1}{1-\sigma}}
$$

units of the domestic currency. The parameter $\sigma$ is the substitution elasticity and the parameter $\nu_{f}$ is a function of the size of country $H$ relative to the rest of the world $n \in(0,1)$ and of the home bias in entry costs, $\lambda_{f} \in(0,1)$, such that $\left(1-\nu_{f}\right)=(1-n) \lambda_{f}$. The entry cost in units of the consumption basket is therefore

$$
f_{t} \frac{P_{f, t}}{P_{t}}
$$

The goods demands per entrant are the solution to the following cost minimization problem

$$
\min _{f_{H, t}, f_{F, t}} f_{t} P_{f, t}=P_{H, t} f_{H, t}+P_{F, t} f_{F, t}
$$

subject to (17). The first order conditions are thus:

$$
\begin{aligned}
f_{H, t} & =\nu_{f}\left(\frac{P_{H, t}}{P_{f, t}}\right)^{-\sigma} f_{t}, \\
f_{F, t} & =\left(1-\nu_{f}\right)\left(\frac{P_{F, t}}{P_{f, t}}\right)^{-\sigma} f_{t} .
\end{aligned}
$$

As in Cavallari (2013), entry requires acquiring a bundle of goods whose composition may differ from that of the consumption basket, defined below. 
It takes one period until an entrant turns into an operational firm. Firms produce each period until they are hit by an exit shock, which occurs with probability $\delta \in(0,1)$ in a given period and affects established and newly created firms equally. In addition, the exit rate of newly established firms consists of the endogenous component $\kappa_{E}\left(N_{E, t-1} / N_{E, t-2}-1\right)^{2} / 2$. The number of producers per industry in period $t$ is thus given by

$$
N_{t}=(1-\delta) N_{t-1}+(1-\delta)\left[1-\frac{\kappa_{E}}{2}\left(\frac{N_{E, t-1}}{N_{E, t-2}}-1\right)^{2}\right] N_{E, t-1} .
$$

This concludes the description of the entry mechanism.

\subsection{Households}

There is a mass $n$ and $(1-n)$ of agents in the home and foreign economy, respectively. Preferences of home households are summarized by:

$$
E_{0} \sum_{t=0}^{\infty} \beta^{t}\left[U\left(c_{t}\right)+V\left(1-l_{H, t}\right)\right]
$$

where $c_{t}$ is the composite good (including both domestic and foreign goods), $l_{H, t}$ is labor, and the time endowment is normalized to unity. $V(\cdot)$ and $U(\cdot)$ are single-period utility functions, which follow the standard continuity and concavity assumptions.

The composite good $c_{t}$ is defined as an aggregate of home-produced goods, $c_{H, t}$, and imports, $c_{F, t}$, with substitution elasticity $\varpi$,

$$
c_{t}=\left[\nu^{\frac{1}{\varpi}}\left(c_{H, t}\right)^{\frac{\varpi-1}{\varpi}}+(1-\nu)^{\frac{1}{\varpi}}\left(c_{F, t}\right)^{\frac{\varpi-1}{\varpi}}\right]^{\frac{\varpi}{\varpi-1}},
$$

where $\nu$ determines the agents' bias towards domestic goods. As in Benigno and De Paoli (2010), $\nu$ is a function of the size of country $H$ relative to the rest of the world $n \in(0,1)$ and of its degree of openness $\lambda \in(0,1)$,

$$
(1-\nu)=(1-n) \lambda
$$

The more open the region (the greater is $\lambda$ ), the lower is the degree of home bias. The larger the region (the greater is $n$ ), the higher is the degree of home bias.

Given a decision on the composite consumption good $c_{t}$, the home household allocates optimally 
the expenditure on domestic and foreign goods, by minimizing total expenditure $P_{t} c_{t}$, subject to the definition in (24). This leads to the following demand functions:

$$
\begin{aligned}
c_{H, t} & =\nu\left(\frac{P_{H, t}}{P_{t}}\right)^{-\varpi} c_{t}, \\
c_{F, t} & =(1-\nu)\left(\frac{P_{F, t}}{P_{t}}\right)^{-\varpi} c_{t} .
\end{aligned}
$$

Replacing $c_{H, t}$ and $c_{F, t}$ in the natural definition of composite expenditure $P_{t} c_{t}=P_{H, t} c_{H, t}+P_{F, t} c_{F, t}$ using (25) and (26), we obtain the following price index for the composite consumption good,

$$
P_{t}=\left[\nu\left(P_{H, t}\right)^{1-\varpi}+(1-\nu)\left(P_{F, t}\right)^{1-\varpi}\right]^{\frac{1}{1-\varpi}},
$$

The home household maximizes utility (23) subject to the period budget constraint given by

$$
\begin{aligned}
& P_{t} c_{t}+\sum_{s^{t+1}} Q\left(s_{t+1} \mid s_{t}\right) D\left(s_{t}\right)+B_{t}+P_{t} v_{t} x_{t}+P_{f, t} f_{t} N_{E, t}+P_{t} T_{t} \leq\left(1-\tau_{t}\right) P_{t} w_{t} l_{H, t} \\
& \quad+R_{t-1} B_{t-1}+D\left(s_{t-1}\right)+(1-\delta) P_{t}\left(v_{t}+d_{t}\right)\left[x_{t-1}+\left(1-\frac{\kappa_{E}}{2}\left(\frac{N_{E, t-1}}{N_{E, t-2}}-1\right)^{2}\right) N_{E, t-1}\right],
\end{aligned}
$$

where $D\left(s_{t}\right)$ are home holdings of state-contingent bonds, traded across countries, which cost $Q\left(s_{t+1} \mid s_{t}\right)$ units of the home currency today and pay one unit of the home currency in state $s_{t+1}$ tomorrow, $B_{t}$ are home holdings of internationally traded risk-free bonds, which cost one home currency unit today and pay $R_{t}$ home currency units tomorrow, $R_{t}$ denoting the nominal interest rate set by the monetary authority, $x_{t}$ are share holdings in domestic firms, of which $N_{t}$ are incumbents and $N_{E, t}$ are new firms, $v_{t}$ is the value of any given firm, $T_{t}$ are lump sum taxes, $w_{t} l_{H, t}$ is labor income, which is taxed at rate $\tau_{t}$.

The first order conditions of the household's problem w.r.t. $l_{H, t}, B_{t}, D\left(s_{t}\right), x_{t}$ and $N_{E, t}$ respectively, are:

$$
\begin{gathered}
\left(1-\tau_{t}\right) w_{t}=-\frac{V_{l_{H}, t}}{U_{c, t}}, \\
1=R_{t} E_{t}\left\{\frac{\Lambda_{t, t+1}}{\pi_{t+1}}\right\}, \\
Q\left(s_{t+1} \mid s_{t}\right)=\operatorname{Pr}\left(s_{t+1} \mid s_{t}\right) \frac{\Lambda_{t, t+1}}{\pi_{t+1}}, \\
v_{t}=(1-\delta) E_{t}\left\{\Lambda_{t, t+1}\left(v_{t+1}+d_{t+1}\right)\right\},
\end{gathered}
$$




$$
\begin{aligned}
\frac{P_{f, t}}{P_{t}} f_{t}= & v_{t}\left(1-\frac{\kappa_{E}}{2}\left(\frac{N_{E, t}}{N_{E, t-1}}-1\right)^{2}-\kappa_{E}\left(\frac{N_{E, t}}{N_{E, t-1}}-1\right) \frac{N_{E, t}}{N_{E, t-1}}\right) \\
& +E_{t}\left\{\Lambda_{t, t+1} v_{t+1} \kappa_{E}\left(\frac{N_{E, t+1}}{N_{E, t}}-1\right)\left(\frac{N_{E, t+1}}{N_{E, t}}\right)^{2}\right\},
\end{aligned}
$$

where

$$
\Lambda_{t-1, t}=\beta \frac{U_{C, t}}{U_{C, t-1}}
$$

is the household's stochastic discount factor, $U_{c}$ denotes the first derivative of $U(\cdot)$ with respect to consumption, $\pi_{t}=\frac{P_{t}}{P_{t-1}}$ is the home CPI inflation rate, $V_{l_{H}}$ is the first derivative of $V(\cdot)$ with respect to labor and $\operatorname{Pr}\left(s_{t+1} \mid s_{t}\right)$ denotes the probability that the state $s_{t+1}$ is observed given $s_{t}$.

\subsection{International Prices}

Demand elasticities are equal across countries, such that the law of one price holds for final goods, i.e. $P_{H, t}=\mathcal{E}_{t} P_{H, t}^{*}$ and $\mathcal{E}_{t} P_{F, t}^{*}=P_{F, t}$, where $\mathcal{E}_{t}$ is nominal exchange rate defined as the home currency price of one unit of the foreign currency. In real terms,

$$
\begin{gathered}
p_{H, t}^{*}=\frac{p_{H, t}}{S_{t}}, \\
p_{F, t}=S_{t} p_{F, t}^{*} .
\end{gathered}
$$

where $S_{t}$ denotes the real exchange rate defined as

$$
S_{t}=\frac{\mathcal{E}_{t} P_{t}^{*}}{P_{t}}
$$

and we have defined the relative prices $p_{H, t}=P_{H, t} / P_{t}, p_{H, t}^{*}=P_{H, t}^{*} / P_{t}^{*}, p_{F, t}=P_{F, t} / P_{t}$ and $p_{F, t}^{*}=P_{F, t}^{*} / P_{t}^{*}$. We also define the terms of trade as

$$
T o T_{t}=\frac{P_{H, t}}{P_{F, t}}=\frac{p_{H, t}}{p_{F, t}}
$$

\subsection{Risk Sharing}

Under perfectly integrated financial markets, home and foreign agents can trade a full set of Arrow-Debreu securities, which implies perfect cross-country risk sharing. Combining the home household's first order conditions for state-contingent bonds (31) and its foreign counterpart, and 
rearranging, we obtain

$$
\Lambda_{t, t+1}=\Lambda_{t, t+1}^{*} \frac{\pi_{t+1}}{\pi_{t+1}^{*}} \frac{\mathcal{E}_{t}}{\mathcal{E}_{t+1}} .
$$

Using the definition of the real exchange rate (37), or in first differences, $\frac{S_{t+1}}{S_{t}}=\frac{\mathcal{E}_{t+1}}{\mathcal{E}_{t}} \frac{\Pi_{t+1}^{*}}{\Pi_{t+1}}$, we obtain the following risk-sharing condition,

$$
\Lambda_{t, t+1}=\Lambda_{t, t+1}^{*} \frac{S_{t}}{S_{t+1}}
$$

stating that the currency's marginal utility growth is equalized across countries. By repeated forward iteration and defining $\varrho=\frac{U_{c, 0} P_{0}^{*}}{U_{c, 0}^{*} P_{0}}$, the risk sharing condition can be written as

$$
S_{t}=\varrho \frac{U_{c, t}^{*}}{U_{c, t}}
$$

Starting from an initial steady state in which consumption and price levels are equal across countries such that $\varrho=1,(40)$ implies that the ratio of marginal utilities at any point in time is equal to the real exchange rate.

\subsection{Monetary and Fiscal Policy}

The fiscal authority finances an exogenous stream of per capita public expenditure $g_{t}$, using labor taxes $\tau_{t}$ and lump sum taxes $T_{t}$. The government's consumption preferences over home final goods and imports are similar to those of the households,

$$
g_{t}=\left[\nu_{g}^{\frac{1}{\varpi}}\left(g_{H, t}\right)^{\frac{\varpi-1}{\varpi}}+\left(1-\nu_{g}\right)^{\frac{1}{\varpi}}\left(g_{F, t}\right)^{\frac{\varpi-1}{\varpi}}\right]^{\frac{\varpi}{\varpi-1}}
$$

where $\left(1-\nu_{g}\right)=(1-n) \lambda_{g}$. Hence, given total government spending $g_{t}$, public consumption of each individual good is given by similar expressions to those obtained for private consumption in equations (25) and (26):

$$
\begin{aligned}
g_{H, t} & =\nu_{g}\left(\frac{P_{H, t}}{P_{g, t}}\right)^{-\varpi} g_{t}, \\
g_{F, t} & =\left(1-\nu_{g}\right)\left(\frac{P_{F, t}}{P_{g, t}}\right)^{-\varpi} g_{t} .
\end{aligned}
$$


Replacing $g_{H, t}$ and $g_{F, t}$ in the natural definition of composite expenditure $P_{g, t} g_{t}=P_{H, t} g_{H, t}+P_{F, t} g_{F, t}$ using (42) and (43), we obtain the following price index for the composite government good,

$$
P_{g, t}=\left[\nu_{g}\left(P_{H, t}\right)^{1-\varpi}+\left(1-\nu_{g}\right)\left(P_{F, t}\right)^{1-\varpi}\right]^{\frac{1}{1-\varpi}}
$$

The domestic government budget constraint (in real per capita terms) is

$$
p_{g, t} g_{t}+R_{t-1} \frac{b_{t-1}}{\pi_{t}}=\tau_{t} w_{t} l_{H, t}+T_{t}+b_{t}
$$

where $p_{g, t}=P_{g, t} / P_{t}$ and $b_{t}=B_{t} / P_{t}$. Real government spending, $G_{t}=p_{g, t} g_{t}$, follows an exogenous $\operatorname{AR}(1)$ process $G_{t}=\left(1-\rho_{g}\right) \log G+\rho_{g} G_{t-1}+\varepsilon_{t}^{g}$, where $\varepsilon_{t}^{g}$ is i.i.d.N $\left(0, \sigma_{\varepsilon^{g}}^{2}\right)$. Labor taxes are assumed to be constant, $\tau_{t}=\tau$.

The monetary authority in the home country sets the interest rate according to a Taylor-type monetary policy rule of the following form:

$$
\log (R / R)=\delta_{r} \log \left(R_{t-1} / R\right)+\left(1-\delta_{r}\right)\left[\delta_{\pi} \log \left(\pi_{t} / \pi\right)+\delta_{y} \log \left(y_{t} / y\right)\right]
$$

where $\delta_{r} \geq 0$ measures the degree of interest rate smoothing and the parameters $\delta_{\pi}>1$ and $\delta_{y} \geq 0$ capture the responsiveness of the nominal interest rate to deviations from inflation and GDP from their steady state values, respectively.

\subsection{Market Clearing and Aggregate Accounting}

Goods market clearing in country $H$ requires aggregate demand for goods produced in country $H$ to be equal to aggregate production, i.e.

$$
\begin{aligned}
y_{H, t}= & c_{H, t}+g_{H, t}+N_{E, t} f_{H, t}+y_{H, t}\left(\pi_{H, t}-1\right)^{2}+\frac{1-n}{n}\left(c_{H, t}^{*}+g_{H, t}^{*}+N_{E, t}^{*} f_{H, t}^{*}\right) \\
= & p_{H, t}^{-\varpi} \nu c_{t}+\left(p_{H, t} / p_{g, t}\right)^{-\varpi} \nu_{g} g_{t}+N_{E, t}\left(p_{H, t} / p_{f, t}\right)^{-\varpi} \nu_{f} f_{t}+y_{H, t}\left(\pi_{H, t}-1\right)^{2} \\
& +(1-n)\left[\left(\frac{p_{H, t}}{S_{t}}\right)^{-\varpi^{*}} \lambda c_{t}^{*}+\left(\frac{p_{H, t}}{S_{t}} \frac{1}{p_{g, t}^{*}}\right)^{-\varpi^{*}} \lambda_{g} g_{t}^{*}+N_{E, t}^{*}\left(\frac{p_{H, t}}{S_{t}} \frac{1}{p_{f, t}^{*}}\right)^{-\sigma^{*}} \lambda_{f} f_{t}^{*}\right],
\end{aligned}
$$

where we have substituted the demand functions (25), (42), (20), and their foreign equivalents, and we have used $p_{H, t}^{*}=\frac{p_{H, t}}{S_{t}}$. 
The market clearing condition for state-contingent bonds reads

$$
n D\left(s_{t}\right)+(1-n) D^{*}\left(s_{t}\right)=0 .
$$

Real GDP is defined as $y_{t}=p_{H, t} y_{H, t}=w_{t} l_{H, t}+d_{t} N_{t}$.

\section{Baseline Calibration and Results}

In the following section, we provide and discuss impulse responses to home government spending expansions in our baseline model. For the calibration, we choose the most conventional parameter values. Our predominant aim is to compare the model predictions with the findings in the empirical and theoretical open economy literature, which has until recently focused on physical capital investment rather firm entry. We are especially interested in the comovement between consumption and investment (at the intensive and extensive margin, respectively) and in the international spillovers of fiscal policy.

\subsection{Functional Forms}

We choose the following functional forms for $U\left(c_{t}\right)$ and $V\left(l_{H, t}\right)$,

$$
U\left(c_{t}\right)=\ln c_{t}, \quad V\left(1-l_{H, t}\right)=\Omega_{H} \ln \left(1-l_{H, t}\right) .
$$

with the first and second derivatives,

$$
U_{c, t}=c_{t}^{-1}, \quad V_{l_{H}, t}=-\frac{\Omega_{H}}{1-l_{H, t}}, \quad U_{c c, t}=-c_{t}^{-2}, \quad V_{l l_{H}, t}=-\frac{\Omega_{H}}{\left(1-l_{H, t}\right)^{2}}
$$

such that $\frac{U_{c c, t} c_{t}}{U_{c, t}}=-1$ and $\frac{V_{l l_{H}, t} l_{H, t}}{V_{l_{H}, t}}=\frac{l_{H, t}}{1-l_{H, t}}$.

\subsection{Parameter Values}

We assume that the home and foreign economy are of the same size, i.e. $n=1 / 2$, and symmetric in terms of parameter values. The discount factor $\beta$ has the value 0.99 , which is conventional for a quarterly frequency as it implies a steady state interest rate of $4(1 / \beta-1)=0.04$ or $4 \%$ per annum. We set the weight on leisure in utility such that steady state hours worked are normalized to $1 / 3$. The degree of openness in the consumption bundle $\lambda$ is calibrated at 0.4 , such that the 
home bias in consumption $\nu$ is equal to 0.8 . The elasticity of substitution in consumption (or trade elasticity) between home and foreign goods is set to $\varpi=1$.

The elasticity of substitution between goods within an industry is set to $\theta_{j}=6$. Following Jaimovich and Floetotto (2008), the substitution elasticity across industries is $\theta_{i}=1.001$, such that $\theta_{j}>\theta_{i}$. This value implies a steady state markup equal to $24 \%$. For the firm exit rate, we set a value of $\delta=0.025$, which corresponds to the commonly used value for capital depreciation in real business cycle models. The cost of adjusting the number of entrants, $\kappa_{E}$, is set to 2 , consistent with the estimate of Lewis and Stevens (2015). Following Cavallari (2013), we set the elasticity of substitution between home and foreign goods in the entry cost bundle, $\sigma$, to unity and we set $\lambda_{f}$ to 0.6 so as to imply that the home bias in entry costs is smaller than the home bias in consumption, $\nu_{f}=0.7$ versus $\nu=0.8$. The productivity shifter $A$ is calibrated such that steady state output is normalized at $y_{H}=1$. We parameterize the cost of price adjustment, $\kappa$, so as to generate a slope of the Phillips curve consistent with a probability of adjusting prices in the Calvo model equal to 0.75. This delivers $\kappa \approx 48$. The coefficients of the Taylor rule measuring the responsiveness of interest rates to inflation and output are set to $\delta_{\pi}=1.5$ and $\delta_{y}=0$, respectively. The interest rate smoothing parameter is set to 0.6. We impose a zero inflation steady state, that is $\pi_{H}=1$.

We assume that imports account for 10 percent of government spending, i.e. we set $\nu_{g}=0.9$ implying an openness coefficent of $\lambda_{g}=0.2$. Government spending is one fifth of domestic output in steady state, i.e. $g / y_{H}=0.2$, which corresponds roughly to the average government spending share in the U.S. The persistence of the government spending process is set to 0.95 . The steady state labor tax rate is set to $\tau=0.28$ which is the value calculated for the U.S. by Trabandt and Uhlig (2011).

\subsection{Baseline Results}

Figure 1 displays the effects of a spending expansion in the home country in the baseline model and calibration.

[ insert Figure 1 here ] 
The solid lines represent the impulse responses in the home economy, while the dashed lines represents the spillover effects to the foreign country.

Home Country Effects of Spending Expansions. The results are very much in line with those shown in Lewis and Winkler (2015), where we focus on a closed-economy setup. The rise in government spending boosts demand for consumption goods. Due to the presence of price adjustment costs, goods prices increase only gradually, such that firms temporarily raise their production levels. Labor demand and real wages rise. As a consequence, inflation responds positively to the shock. As argued by Linnemann and Schabert (2003) and Corsetti et al. (2010), the inflation response depends to a large extent on the specification of the monetary policy rule. Here, we assume a fairly 'hawkish' central bank, whose primary aim is to stabilize inflation via an interest rate feedback rule.

There is a strong negative wealth effect from tax-financed government spending shocks such that private consumption is reduced. ${ }^{3}$ With a sufficiently persistent spending expansion, the rise in the present discounted sum of future profits boosts firm value, providing an incentive for new firms to enter the market. Firm entry, or extensive-margin investment, increases. Thus, in contrast to the predictions in Corsetti et al. (2010)'s model with physical capital, as well as empirical evidence in Lewis and Winkler (2015), consumption and investment do not comove in our baseline framework.

International Spillovers from Spending Expansions. The responses of international prices to government spending shocks are in line with the Mundell-Fleming model, see Figure 1. The terms of trade improve as export prices rise above import prices and accordingly, the real exchange rate appreciates. The main reason that home goods become dearer relative to imported goods is that government spending falls disproportionately on home products. The appreciation of the domestic currency benefits home entrants, who have to import foreign goods when starting a new firm: a real appreciation lowers entry costs, see (19).

Net exports fall after a spending expansion, as in the model with physical capital, see Corsetti

\footnotetext{
${ }^{3}$ Lewis and Winkler (2015) discuss various model extensions that generate consumption crowding-in from fiscal expansions in a closed-economy endogenous-entry model. One such extension, useful government spending, is considered below.
} 
et al. (2010). As pointed out by Schmitt-Grohe and Uribe (2015), introducing investment into the model helps to generate countercyclical movements in the trade balance, consistent with the data.

Figure 1 suggests that the output spillovers to the foreign country are small under our baseline calibration. The limited output spillover can by explained by two countervailing effects on foreign GDP. On the one hand, the appreciation of the domestic currency leads to an expenditureswitching effect in favor of foreign goods, which boosts foreign net exports. The improvement in the trade balance is reinforced by the domestic government expansion which raises the demand for foreign goods (recall that under our baseline calibration, the governments consume foreign and domestic goods). On the other hand, foreign consumption and firm entry decline. The drop in foreign consumption can by a explained by the rise in the foreign real interest rate, which induces households to postpone consumption. The real appreciation of the home currency makes imports more expensive in the foreign country, raising entry costs for would-be entrepreneurs in country $F$. As a results, fewer new firms enter the market there.

\section{Sensitivity Analysis}

In the Mundell-Fleming model, international spillovers are greater, the more open is the country, i.e. the greater the marginal propensity to import. The smaller the domestic economy, the less significant it is as a buyer for its trading partner, and therefore the smaller the spillover effect. A country with a fixed exchange rate will enjoy a greater boost to output because an accommodative monetary policy stance is warranted to keep the exchange rate from appreciating.

To investigate whether the Mundell-Fleming intuition also applies in our endogenous-entry framework, we now carry out a sensitivity analysis of our baseline results to four parameter perturbations and to the case of fixed exchange rates. First, we explore the importance of country size. Second, we vary the share of goods that entrants need to import when setting up a new firm. Third, we explore the role of the share of imported goods in the government spending bundle for our results. Fourth, we vary the elasticity of home versus foreign goods in consumption to values lower or higher than unity, which reduces or enhances the expenditure-switching effect. Finally, we repeat all our parameter variations for the case of a fixed exchange rate regime. 
For each exercise, we condense the fiscal policy effects into one metric: the cumulative fiscal multipliers at the 12-quarter horizon. The multipliers are computed as the cumulative change in a variable of interest relative to the cumulative change in government spending during the first 12 quarters. For domestic GDP and domestic consumption, the multipliers are expressed in units of the domestic currency. For all other variables of interest, the multipliers are expressed in elasticity form, i.e. they are computed as the sum of the cumulative percentage change of the respective variable relative to the cumulative percentage change in government spending during the first 12 quarters.

The results of our sensitivity analysis are shown in Figure 2. The rows show fiscal multipliers for the variables of interest, the columns present results for the different parameter perturbations. The solid lines in each panel display results under floating exchange rates, the 'stars' mark results of our baseline scenario discussed above. The dashed lines display results in the case of fixed exchange rates between the two countries, the ' $\mathrm{x}$ '-marks are the multipliers under our baseline calibration but with fixed exchange rates.

[ insert Figure 2 here ]

Varying Country Size. We can change the relative size of the home country by varying the parameter $n$. It is common practice to consider a small open economy as the limiting case where $n$ approaches zero, see for example Benigno and De Paoli (2010). The case where $n$ approaches unity corresponds to the closed economy case.

It is clear that shocks to the home country have an ever smaller effect on the foreign country as $n$ approaches zero. In general, the spillovers on foreign GDP and firm entry increase (in absolute value) with increasing size of the domestic economy.

In the domestic economy, there is less consumption crowding out in country $H$ if country size $n$ declines because the hike in the real interest rate is dampened. This also reduces the negative effects of spending shocks on firm entry in the home country. However, in contrast to Corsetti et al. (2010), lower country size decreases the output multiplier. The reason is that the home bias in government consumption declines if the home country becomes smaller; a larger part of 
the spending expansion falls on foreign goods which lowers net exports and pushes down domestic income.

Varying the Share of Imported Goods in Entry Bundle. The importance of an import content in the entry cost bundle for the spillover effects of technology shocks is emphasized in Cavallari (2013). Here, we explore the role of this channel for the cross-country transmission of spending shocks. More precisely, we vary the degree of openness $\lambda_{f}=\lambda_{f}^{*}$ between zero (implying no foreign goods in the entry bundle, i.e. $\nu_{f}=1$ and $\nu_{f}^{*}=0$ ) to unity (implying $\nu_{f}=\nu_{f}^{*}=0.5$ ).

The responses of domestic GDP, domestic consumption and foreign GDP remain largely unaffected by this parameter change. However, the effect on the firm entry responses are substantial. As the domestic currency appreciates, entry costs in the home country decline whereas entry becomes more expensive in the foreign economy. The larger the share of foreign goods in the entry bundle, the stronger is this entry cost channel. As a consequence, the entry multipliers increase (in absolute value) with a rising import share.

Varying the Share of Imported Goods in Government Consumption Bundle. The third column in Figure 2 display multipliers for alternative values of the share of imported goods in the government consumption bundle ranging from $\lambda_{g}=\lambda_{g}^{*}=0$ (implying that the government consumes no foreign goods, i.e. $\nu_{f}=1$ and $\nu_{f}^{*}=0$ ) to $\lambda_{g}=\lambda_{g}^{*}=1$ (implying equal shares $\left.\nu_{f}=\nu_{f}^{*}=0.5\right)$.

The output multiplier in the home country declines if a larger part of the government spending expansion falls on foreign goods; by the same argument the foreign multiplier increases. As the degree of openness approaches unity, foreign income rises considerably which, in turn, boosts investment; the foreign entry response turns positive. In the limiting case where the domestic government does not buy foreign goods, the output spillover becomes negative. In that case, the rise in foreign net exports is not strong enough to outweigh the negative effects of the decline in consumption and investment.

Varying the Substitution Elasticity between Home Goods and Imports. The substitution elasticity between home and foreign goods, $\varpi$, plays an important role for the expenditure 
switching effect and thus for the international transmission of shocks. This elasticity is usually assumed to be greater than unity, which implies that home and foreign goods are highly substitutable. If, instead, this elasticity is lower than unity, substitutability and therefore expenditure switching by consumers is also low.

We can see from Figure 2 that the drop in net exports is stronger, the larger is the trade elasticity $\varpi$. The result is intuitive: domestic households are more inclined to switch their expenditure to imports if the domestic currency appreciates and domestic goods become more expensive. Likewise, foreign households are more inclined to switch their expenditure to goods produced in country $\mathrm{F}$ (or domestically-produced goods from the perspective of the foreign economy) as they become relatively cheaper. As a consequence, the rise in GDP is smaller if the trade elasticity increases. This, in turn, lowers firm entry. The spillover of the fiscal expansion on foreign economy's income becomes considerably positive for large values of the trade elasticity. On the contrary, if the trade elasticity is small, the foreign economy benefits less from the appreciation of the domestic currency; the effect on foreign income turns negative. The fall in investment is amplified if the elasticity of substitution between home goods and imports shrinks. This can be explained by the fall in foreign income and the stronger rise in the real exchange rate which, in turn, raises entry costs relative to the case in which the trade elasticity is large.

Fixed Exchange Rates. The textbook Mundell-Fleming model is still the most widely used framework to think about macroeconomic policies and international spillovers under different exchange rate regimes. Under flexible exchange rates, a spending expansion leads to a short-run rise in the home interest rate, which puts upward pressure on the price of the home currency. The ensuing appreciation lowers net exports, reducing the demand for home goods and ultimately dampening the expansionary short-run effect on home output. In contrast, under fixed exchange rates, the central bank is required to loosen monetary policy in order to avoid an exchange rate appreciation and preserve the peg. This accommodative monetary policy stance reduces interest rates and stimulates investment at home, which boosts the expansionary short-run effect on home output.

With extensive-margin investment, the observed effect of fixed exchange rates is similar to the 
Mundell-Fleming setup: firm entry rises more than in the baseline scenario with flexible exchange rates. This is not surprising given that the entry process involves a forward-looking decision that depends a great deal on the expected future interest rate path. The fall in consumption is less pronounced under fixed exchange rates. Overall, the multiplier is larger when the exchange rate is fixed. Under our baseline calibration, the spillover on the foreign economy is barely affected by a change in the exchange rate regime, see the dashed and solid lines in Figure 2.

Summary. The analysis so far has shown that sizable foreign output spillovers of a domestic fiscal expansion occur if the trade elasticity is high or if a substantial part of the spending expansion falls on goods produced in the foreign economy. Both parameter choices seem to be implausible from an empirical perspective. Moreover, the model robustly generates a fall in private consumption, which is at odds with empirical evidence suggesting that spending expansions stimulate consumption and firm entry in the home country. We now analyze whether extending the model by considering useful government spending can help to reconcile the model with the data.

\section{Model Extension: Useful Government Spending}

In this section, we consider useful government spending as in Lewis and Winkler (2015). In that paper, we show that it is difficult to generate a comovement between consumption and firm entry in the closed-economy model, because consumption is usually crowded out while firm entry typically rises for highly persistent spending shocks. This is inconsistent with the empirical evidence where both variables tend to rise after such as shock. One model feature that generates comovement is utility- or productivity-enhancing government spending.

We adopt the first assumption here, supposing that government spending directly enters the household's utility function, e.g. in the form of public good provision. Consumption utility is derived from a composite of private and public consumption,

$$
\tilde{c}_{t}=\left[\xi c_{t}^{\gamma}+(1-\xi) g_{t}^{\gamma}\right]^{\frac{1}{\gamma}}
$$

where $\gamma \in(-\infty, 1)$ and $\xi \in(0,1]$. The elasticity of substitution between private and public goods is $\frac{1}{1-\gamma}$. The benchmark model in which government spending does not provide utility is 
given by $\xi=1$. Utility is logarithmic in the composite, $U\left(\tilde{c}_{t}\right)=\ln \tilde{c}_{t}$. The marginal utility of private consumption is $U_{c, t}=\xi c_{t}^{\gamma-1} \tilde{c}_{t}^{-\gamma}$. We restrict attention to the case where public and private consumption are complements, such that the marginal utility of private consumption is increasing in government spending. Formally, in the log-utility case complementarity is obtained if $\frac{\partial U_{c, t}}{\partial g_{t}}>0$, which is the case if $\gamma<0$. We set this value to $\gamma=-0.5$.

We present the results of this model extension in two formats. Figure 3 shows impulse responses of GDP, consumption, firm entry and international relative prices to a rise in government spending when we set the share of government spending in the consumption composite, $(1-\xi)$, to 0.2 . The fifth column of Figure 2 displays fiscal multipliers for alternative values of $(1-\xi)$ ranging from $(1-\xi)=0$ to $(1-\xi)=0.5$, where units on the horizontal axes are values for $\xi$.

\section{[ insert Figure 3 here ]}

As expected, the consumption response in the home country turns positive if the share parameter $(1-\xi)$ is sufficiently large. The larger is the share of government spending in the consumption composite, the stronger is the increase in consumption and GDP. Inspecting Figure 2 reveals that the income multiplier becomes considerably larger than one if $(1-\xi)$ approaches its lower limit. A rise in domestic consumption fuels profit opportunities and induces more firms to enter the market. The output boom in the home country enhances the appreciation of the domestic currency. Domestic net exports decline more strongly, the larger is the share parameter $(1-\xi)$. In the foreign economy, the pattern for the real exchange rate implies that GDP rises (due to a rise in foreign net exports) and firm entry declines (due to a rise in entry costs) as $(1-\xi)$ and thus the real depreciation of the foreign currency increases.

All in all, the extended model with useful government spending generates a joint rise in private consumption and extensive-margin investment after a government spending expansion in the home country. It also generates sizable positive output spillovers due to favorable movements in foreign net exports and international relative prices. 


\section{Conclusion}

This paper analyzes the international effects of government spending in a sticky-price model where investment takes the form of new firms producing new differentiated products. We document that consumption and investment do not comove in the baseline model and cross-country spillovers tend to be small. These results run counter to the empirical evidence, which points towards a joint rise in private consumption and extensive-margin investment after a government spending expansion in the home country, see Lewis and Winkler (2015). Moreover, the literature provides evidence of real exchange rate appreciations together with positive output spillovers to foreign economies after domestic fiscal expansions, see Canzoneri et al. (2003). Our sensitivity analysis shows that the effects of a domestic spending expansion on the home country and spillovers to the foreign economy depend crucially on the share of foreign goods in the entry process, on the trade elasticity and on whether government spending is useful. In this regard, our analysis suggests that a model with useful government spending performs best in replicating the empirical evidence.

\section{References}

[1] Auerbach, Alan J. and Yuriy Gorodnichenko (2015). Effects of Fiscal Shocks in a Globalized World. NBER Working Paper 21100. National Bureau of Economic Research.

[2] Auerbach, Alan J. and Yuriy Gorodnichenko (2013). Output Spillovers from Fiscal Policy. American Economic Review 103(3), 141-146.

[3] Beetsma, Roel; Massimo Giuliodori and Franc Klaassen (2006). Trade spill-overs of fiscal policy in the European Union: a panel analysis. Economic policy 21(48), 640-687.

[4] Benetrix, Agustin S. and Philip R. Lane (2013). Fiscal Shocks and the Real Exchange Rate. International Journal of Central Banking 9(3), 1-32.

[5] Benigno, Gianluca and Bianca De Paoli (2010). On the International Dimension of Fiscal Policy. Journal of Money, Credit and Banking 42(8), 1523-1542.

[6] Bilbiie, Florin O.; Fabio Ghironi and Marc J. Melitz (2008). Monetary Policy and Business Cycles with Endogenous Entry and Product Variety. NBER Chapters, in: NBER Macroe- 
conomics Annual 2007, Volume 22, pages 299-353, National Bureau of Economic Research, Inc.

[7] Bilbiie, Florin O.; Fabio Ghironi and Marc J. Melitz (2012). Endogenous Entry, Product Variety, and Business Cycles. Journal of Political Economy 120(2), 304 - 345.

[8] Born, Benjamin; Falko Jüssen and Gernot J. Müller (2013). Exchange rate regimes and fiscal multipliers. Journal of Economic Dynamics and Control 37(2), 446-465.

[9] Canzoneri, Matthew B.; Robert E. Cumby and Behzad T. Diba (2003). New Views on the Transatlantic Transmission of Fiscal Policy and Macroeconomic Policy Coordination. In: Monetary and Fiscal Policies in EMU, ed. M. Buti, 283-311. Cambridge University Press.

[10] Cavallari, Lilia (2013). Firms' Entry, Monetary Policy and the International Business Cycle. Journal of International Economics 91(2), 263-274.

[11] Corsetti, Giancarlo; André Meier and Gernot J. Müller (2010). Cross-Border Spillovers from Fiscal Stimulus. International Journal of Central Banking 6(1), 5-37.

[12] Devereux, Michael B. and Khang Min Lee (2001). Dynamic Gains from International Trade with Imperfect Competition and Market Power. Review of Development Economics 5(2), 23955.

[13] Enders, Zeno; Gernot J. Müller and Almuth Scholl (2011). How do fiscal and technology shocks affect real exchange rates?: New evidence for the United States. Journal of International Economics 83(1), 53-69.

[14] Galí, Jordi and Tommaso Monacelli (2008). Optimal Monetary and Fiscal Policy in a Currency Union. Journal of International Economics 76, 116-132.

[15] Jaimovich, Nir and Max Floetotto (2008). Firm Dynamics, Markup Variations, and the Business Cycle. Journal of Monetary Economics 55, 1238-1252.

[16] Lewis, Vivien and Arnoud Stevens (2015). Entry and markup dynamics in an estimated business cycle model. European Economic Review 74, 14-35. 
[17] Lewis, Vivien and Roland Winkler (2015). Government Spending, Entry and the Consumption Crowding-In Puzzle. Manuscript, KU Leuven and TU Dortmund University.

[18] Linnemann, Ludger and Andreas Schabert (2003). Fiscal Policy in the New Neoclassical Synthesis. Journal of Money, Credit and Banking 35(6), 911-29.

[19] Monacelli, Tommaso and Roberto Perotti (2010). Fiscal Policy, the Real Exchange Rate and Traded Goods. Economic Journal 120(544), 437-461.

[20] Ravn, Morten O.; Stephanie Schmitt-Grohe and Martin Uribe (2012). Consumption, government spending, and the real exchange rate. Journal of Monetary Economics 59(3), 215-234.

[21] Uribe, Martín and Stephanie Schmitt-Grohe (2015). Open Economy Macroeconomics. Textbook manuscript.

[22] Trabandt, Mathias and Harald Uhlig (2011). The Laffer curve revisited. Journal of Monetary Economics 58(4), 305-327. 


\section{Appendix}

\section{Derivations for the Foreign Economy}

In the foreign country, the final good and the industry goods are given by the following aggregator functions

$$
\begin{gathered}
Y_{F, t}^{*}=\left[\left(\frac{1}{1-n}\right)^{\frac{1}{\theta_{i}^{*}}} \int_{n}^{1} y_{F, t}^{*}\left(i^{*}\right)^{\frac{\theta_{i}^{*}-1}{\theta_{i}^{*}}} d i^{*}\right]^{\frac{\theta_{i}^{*}}{\theta_{i}^{*}-1}}, \\
y_{F, t}^{*}\left(i^{*}\right)=\left[\left(\frac{1}{1-n}\right)^{\frac{1}{\theta_{j}^{*}}} \sum_{j^{*}=1}^{N_{t}^{*}\left(i^{*}\right)} y_{F, t}^{*}\left(i^{*}, j^{*}\right)^{\frac{\theta_{j}^{*}-1}{\theta_{j}^{*}}}\right]^{\frac{\theta_{j}^{*}}{\theta_{j}^{*}-1}},
\end{gathered}
$$

where $i^{*} \in(n, 1)$ indexes the industries in the foreign country $j^{*}=1, \ldots, N_{t}^{*}\left(i^{*}\right)$ indexes the firms active in the foreign industry $i^{*}$, and $(1-n)$ is the relative size of the foreign economy. The production function and profits are

$$
\begin{gathered}
y_{F, t}^{*}\left(i^{*}, j^{*}\right)=A_{t}^{*} l_{F, t}^{*}\left(i^{*}, j^{*}\right), \\
d_{t}^{*}\left(i^{*}, j^{*}\right)=\frac{P_{F, t}^{*}\left(i^{*}, j^{*}\right)}{P_{t}^{*}} y_{F, t}^{*}\left(i^{*}, j^{*}\right)-w_{t}^{*} l_{F, t}^{*}\left(i^{*}, j^{*}\right) \\
-\frac{\kappa *}{2}\left(\frac{P_{F, t}^{*}\left(i^{*}, j^{*}\right)}{P_{F, t-1}^{*}\left(i^{*}, j^{*}\right)}-1\right)^{2} \frac{P_{F, t}^{*}\left(i^{*}, j^{*}\right)}{P_{t}^{*}} y_{F, t}^{*}\left(i^{*}, j^{*}\right) .
\end{gathered}
$$

The corresponding equations for price setting and desired markups in a symmetric equilibrium are, respectively,

$$
\begin{aligned}
\pi_{F, t}^{*}\left(\pi_{F, t}^{*}-1\right)= & \frac{\varepsilon_{t}^{*}}{\kappa^{*}}\left(\frac{P_{t}^{*}}{P_{F, t}^{*}} \frac{w_{t}^{*}}{A_{t}^{*}}-\frac{1}{\mu_{t}^{d *}}\left[1-\frac{\kappa}{2}\left(\pi_{F, t}^{*}-1\right)^{2}\right]\right) \\
& +E_{t}\left\{\Lambda_{t, t+1}^{*} \pi_{F, t+1}^{*}\left(\pi_{F, t+1}^{*}-1\right) \frac{\pi_{F, t+1}^{*}}{\pi_{t+1}^{*}} \frac{y_{F, t+1}^{*}}{y_{F, t}^{*}} \frac{N_{t}^{*}}{N_{t+1}^{*}}\right\},
\end{aligned}
$$

and

$$
\mu_{t}^{d *}=\frac{\theta_{j}^{*} N_{t}^{*}-\left(\theta_{j}^{*}-\theta_{i}^{*}\right)}{\left(\theta_{j}^{*}-1\right) N_{t}^{*}-\left(\theta_{j}^{*}-\theta_{i}^{*}\right)} .
$$

The foreign household solves analogous allocation problems as the home household. The consumption bundle in the foreign country is defined as

$$
c_{t}^{*}=\left[\left(\nu^{*}\right)^{\frac{1}{\varpi^{*}}}\left(c_{H, t}^{*}\right)^{\frac{\varpi^{*}-1}{\varpi^{*}}}+\left(1-\nu^{*}\right)^{\frac{1}{\varpi^{*}}}\left(c_{F, t}^{*}\right)^{\frac{\varpi^{*}-1}{\varpi^{*}}}\right]^{\frac{\varpi^{*}}{\varpi^{*}-1}},
$$


where the degree of home bias in $F$ is related to country $H$ 's size and openness through $\nu^{*}=n \lambda$. We have the following optimality conditions for the home and foreign bundles,

$$
\begin{aligned}
c_{H, t}^{*} & =\nu^{*}\left(\frac{P_{H, t}^{*}}{P_{t}^{*}}\right)^{-\varpi^{*}} c_{t}^{*}, \\
c_{F, t}^{*} & =\left(1-\nu^{*}\right)\left(\frac{P_{F, t}^{*}}{P_{t}^{*}}\right)^{-\varpi^{*}} c_{t}^{*} .
\end{aligned}
$$

Using (55) and (56), we replace $c_{H}^{*}$ and $c_{F}^{*}$ in the natural definition of the composite expenditure $P_{t}^{*} c_{t}^{*}=P_{H, t}^{*} c_{H, t}^{*}+P_{F, t}^{*} c_{F, t}^{*}$ to get the associated price index

$$
P_{t}^{*}=\left[\nu^{*}\left(P_{H, t}^{*}\right)^{1-\varpi^{*}}+\left(1-\nu^{*}\right)\left(P_{F, t}^{*}\right)^{1-\varpi^{*}}\right]^{\frac{1}{1-\varpi^{*}}},
$$

In country $F$, the representative agent chooses consumption, production and asset holdings to maximize

$$
E_{0} \sum^{\infty} \beta^{t}\left[U\left(c_{t}^{*}\right)+V\left(1-l_{F, t}^{*}\right)\right]
$$

subject to the budget constraint given by

$$
\begin{aligned}
& P_{t}^{*} c_{t}^{*}+\sum_{s^{t+1}} Q\left(s_{t+1} \mid s_{t}\right) \frac{D^{*}\left(s_{t}\right)}{\mathcal{E}_{t}}+B_{t}^{*}+P_{t}^{*} v_{t}^{*} x_{t}^{*}+P_{f, t}^{*} f_{t}^{*} N_{E, t}^{*}+P_{t}^{*} T_{t}^{*} \leq\left(1-\tau_{t}^{*}\right) P_{t}^{*} w_{t}^{*} l_{F, t}^{*} \\
& +R_{t-1}^{*} B_{t-1}^{*}+\frac{D^{*}\left(s_{t-1}\right)}{\mathcal{E}_{t}}+\left(1-\delta^{*}\right) P_{t}^{*}\left(v_{t}^{*}+d_{t}^{*}\right)\left[x_{t-1}^{*}+\left(1-\frac{\kappa_{E}^{*}}{2}\left(\frac{N_{E, t-1}^{*}}{N_{E, t-2}^{*}}-1\right)^{2}\right) N_{E, t-1}^{*}\right]
\end{aligned}
$$

where the nominal exchange rate, denoted $\mathcal{E}_{t}$, is the home currency price of one unit of the foreign currency. The corresponding first order conditions for the foreign household w.r.t. $l_{F, t}^{*}, B_{t}^{*}, D^{*}\left(s_{t}\right)$, $x_{t}^{*}$ and $N_{E, t}^{*}$ respectively, are:

$$
\begin{gathered}
\left(1-\tau_{t}^{*}\right) w_{t}^{*}=-\frac{V_{l_{F}, t}^{*}}{U_{c, t}^{*}}, \\
1=R_{t}^{*} E_{t}\left\{\frac{\Lambda_{t, t+1}^{*}}{\pi_{t+1}^{*}}\right\}, \\
Q\left(s_{t+1} \mid s_{t}\right)=\operatorname{Pr}\left(s_{t+1} \mid s_{t}\right) \frac{\Lambda_{t, t+1}^{*}}{\pi_{t+1}^{*}} \frac{\mathcal{E}_{t}}{\mathcal{E}_{t+1}}, \\
v_{t}^{*}=\left(1-\delta^{*}\right) E_{t}\left\{\Lambda_{t, t+1}^{*}\left(v_{t+1}^{*}+d_{t+1}^{*}\right)\right\},
\end{gathered}
$$




$$
\begin{aligned}
\frac{P_{f, t}^{*}}{P_{t}^{*}} f_{t}^{*}= & v_{t}^{*}\left(1-\frac{\kappa_{E}^{*}}{2}\left(\frac{N_{E, t}^{*}}{N_{E, t-1}^{*}}-1\right)^{2}-\kappa_{E}^{*}\left(\frac{N_{E, t}^{*}}{N_{E, t-1}^{*}}-1\right) \frac{N_{E, t}^{*}}{N_{E, t-1}^{*}}\right) \\
& +E_{t}\left\{\Lambda_{t, t+1}^{*} v_{t+1}^{*} \kappa_{E}^{*}\left(\frac{N_{E, t+1}^{*}}{N_{E, t}^{*}}-1\right)\left(\frac{N_{E, t+1}^{*}}{N_{E, t}^{*}}\right)^{2}\right\},
\end{aligned}
$$

where

$$
\Lambda_{t-1, t}^{*}=\beta^{*} \frac{U_{C, t}^{*}}{U_{C, t-1}^{*}} .
$$

In the foreign country, the entry cost and its price, the goods demands by an individual entrant, and the law of motion describing the number firms are, respectively,

$$
f_{t}^{*}=\left[\nu_{f}^{\frac{1}{\sigma^{*}}}\left(f_{H, t}^{*}\right)^{\frac{\sigma^{*}-1}{\sigma^{*}}}+\left(1-\nu_{f}^{*}\right)^{\frac{1}{\sigma^{*}}}\left(f_{F, t}^{*}\right)^{\frac{\sigma^{*}-1}{\sigma^{*}}}\right]^{\frac{\sigma^{*}}{\sigma^{*}-1}}
$$

where $\nu_{f}^{*}=n \lambda_{f}$,

$$
\begin{gathered}
P_{f, t}^{*}=\left[\nu_{f}^{*}\left(P_{H, t}^{*}\right)^{1-\sigma^{*}}+\left(1-\nu_{f}^{*}\right)\left(P_{F, t}^{*}\right)^{1-\sigma^{*}}\right]^{\frac{1}{1-\sigma^{*}}}, \\
f_{H, t}^{*}=\nu_{f}^{*}\left(\frac{P_{H, t}^{*}}{P_{f, t}^{*}}\right)^{-\sigma^{*}} f_{t}^{*}, \\
f_{F, t}^{*}=\left(1-\nu_{f}^{*}\right)\left(\frac{P_{F, t}^{*}}{P_{f, t}^{*}}\right)^{-\sigma^{*}} f_{t}^{*},
\end{gathered}
$$

and

$$
N_{t}^{*}=\left(1-\delta^{*}\right) N_{t-1}^{*}+\left(1-\delta^{*}\right)\left[1-\frac{\kappa_{E}^{*}}{2}\left(\frac{N_{E, t-1}^{*}}{N_{E, t-2}^{*}}-1\right)^{2}\right] N_{E, t-1}^{*} .
$$

The foreign government's preferences and budget constraint are defined analogously:

$$
g_{t}^{*}=\left[\left(\nu_{g}^{*}\right)^{\frac{1}{\varpi^{*}}}\left(g_{H, t}^{*}\right)^{\frac{\varpi^{*}-1}{\varpi^{*}}}+\left(1-\nu_{g}^{*}\right)^{\frac{1}{\varpi^{*}}}\left(g_{F, t}^{*}\right)^{\frac{\varpi^{*}-1}{\varpi^{*}}}\right]^{\frac{\varpi^{*}}{\varpi^{*}-1}},
$$

where $\nu^{*}=n \lambda_{g}$. The associated demand functions for the home- and foreign-produced goods are

$$
\begin{aligned}
g_{H, t}^{*} & =\nu_{g}^{*}\left(\frac{P_{H, t}^{*}}{P_{g, t}^{*}}\right)^{-\varpi^{*}} g_{t}^{*}, \\
g_{F, t}^{*} & =\left(1-\nu_{g}^{*}\right)\left(\frac{P_{F, t}^{*}}{P_{g, t}^{*}}\right)^{-\varpi^{*}} g_{t}^{*} .
\end{aligned}
$$


The corresponding price index reads

$$
P_{g, t}^{*}=\left[\nu_{g}^{*}\left(P_{H, t}^{*}\right)^{1-\varpi^{*}}+\left(1-\nu_{g}^{*}\right)\left(P_{F, t}^{*}\right)^{1-\varpi^{*}}\right]^{\frac{1}{1-\varpi^{*}}} .
$$

The foreign government budget constraint (in terms of foreign output) is

$$
p_{g, t}^{*} g_{t}^{*}+R_{t-1}^{*} \frac{b_{t-1}^{*}}{\pi_{t}^{*}}=\tau_{t}^{*} w_{t}^{*} l_{F, t}^{*}+T_{t}^{*}+b_{t}^{*}
$$

where $p_{g, t}^{*}=P_{g, t}^{*} / P_{t}^{*}$. In the foreign economy, goods purchases of the government and taxes are assumed to be constant, i.e. $g_{t}^{*}=g^{*}$ and $\tau_{t}^{*}=\tau^{*}$.

The interest rate rule for the foreign economy is given by

$$
\log \left(R_{t}^{*} / R^{*}\right)=\delta_{r}^{*} \log \left(R_{t-1}^{*} / R^{*}\right)+\left(1-\delta_{r}^{*}\right)\left[\delta_{\pi}^{*} \log \left(\pi_{t}^{*} / \pi^{*}\right)+\delta_{y} \log \left(y_{t}^{*} / y^{*}\right)\right]
$$

The market clearing condition for good produced in $F$ reads

$$
\begin{aligned}
y_{F, t}^{*}= & c_{F, t}^{*}+g_{F, t}^{*}+N_{E, t}^{*} f_{F, t}^{*}+y_{F, t}^{*}\left(\pi_{F, t}^{*}-1\right)^{2}+\frac{n}{1-n}\left(c_{F, t}+g_{F, t}+N_{E, t} f_{F, t}\right) \\
= & \left(p_{F, t}^{*}\right)^{-\varpi^{*}}\left(1-\nu^{*}\right) c_{t}^{*}+\left(\frac{p_{F, t}^{*}}{p_{g, t}^{*}}\right)^{-\varpi^{*}}\left(1-\nu_{g}^{*}\right) g_{t}^{*}+N_{E, t}^{*}\left(\frac{p_{F, t}^{*}}{p_{f, t}^{*}}\right)^{-\sigma^{*}}\left(1-\nu_{f}^{*}\right) f_{t}^{*}+y_{F, t}^{*}\left(\pi_{F, t}^{*}-1\right)^{2} \\
& +n\left[\left(S_{t} p_{F, t}^{*}\right)^{-\varpi} \lambda c_{t}+\left(S_{t} p_{F, t}^{*} / p_{g, t}\right)^{-\varpi} \lambda_{g} g_{t}+N_{E, t} \lambda_{f}\left(S_{t} p_{F, t}^{*} / p_{f, t}\right)^{-\sigma} f_{t}\right],
\end{aligned}
$$

where we have substituted the demand functions (26), (43), (21), and their foreign equivalents, and we have used $p_{F, t}=S_{t} p_{F, t}^{*}$ from the pricing condition (36).

Finally, foreign real GDP is defined as

$$
y_{t}^{*}=p_{F, t}^{*} y_{F, t}^{*}=w_{t}^{*} l_{F, t}^{*}+d_{t}^{*} N_{t}^{*} .
$$




\section{Figures}

Figure 1: Effects of Domestic Government Spending Expansion.
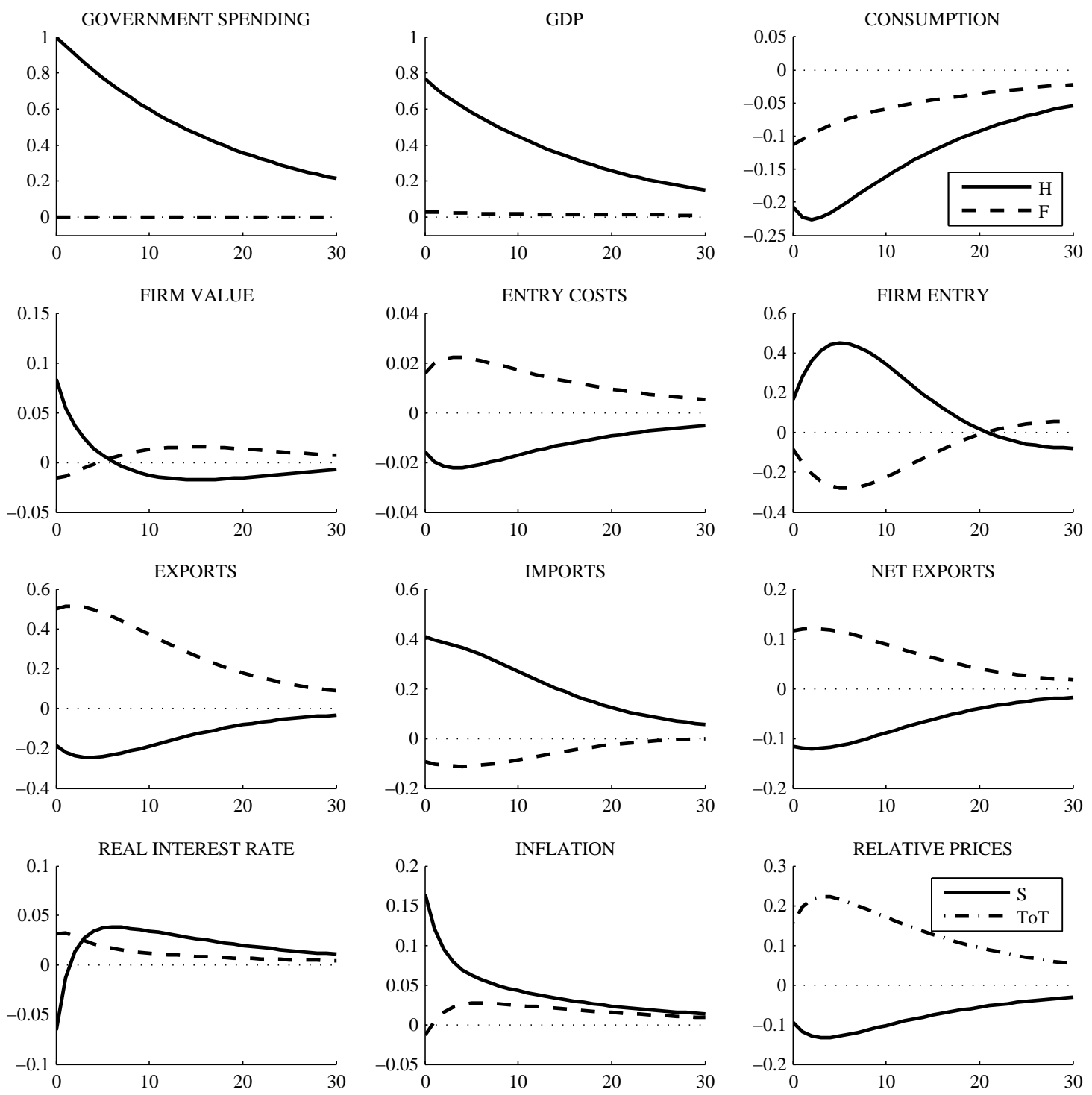

Notes: Solid lines show responses of domestic variables $(H)$, dashed lines show responses of foreign variables $(F)$. The lower right panel shows responses of the real exchange rate $S=\mathcal{E} P^{*} / P$ (solid line) and the terms of trade $T o T=P_{H} / P_{F}$ (dashed-dotted line). Responses are expressed in percentage deviations from steady state with the exception of the response of the real interest rate that is given in annualized percentage-point deviations from steady state. The horizontal axes measure time in quarters. 
Figure 2: Sensitivity Analysis.
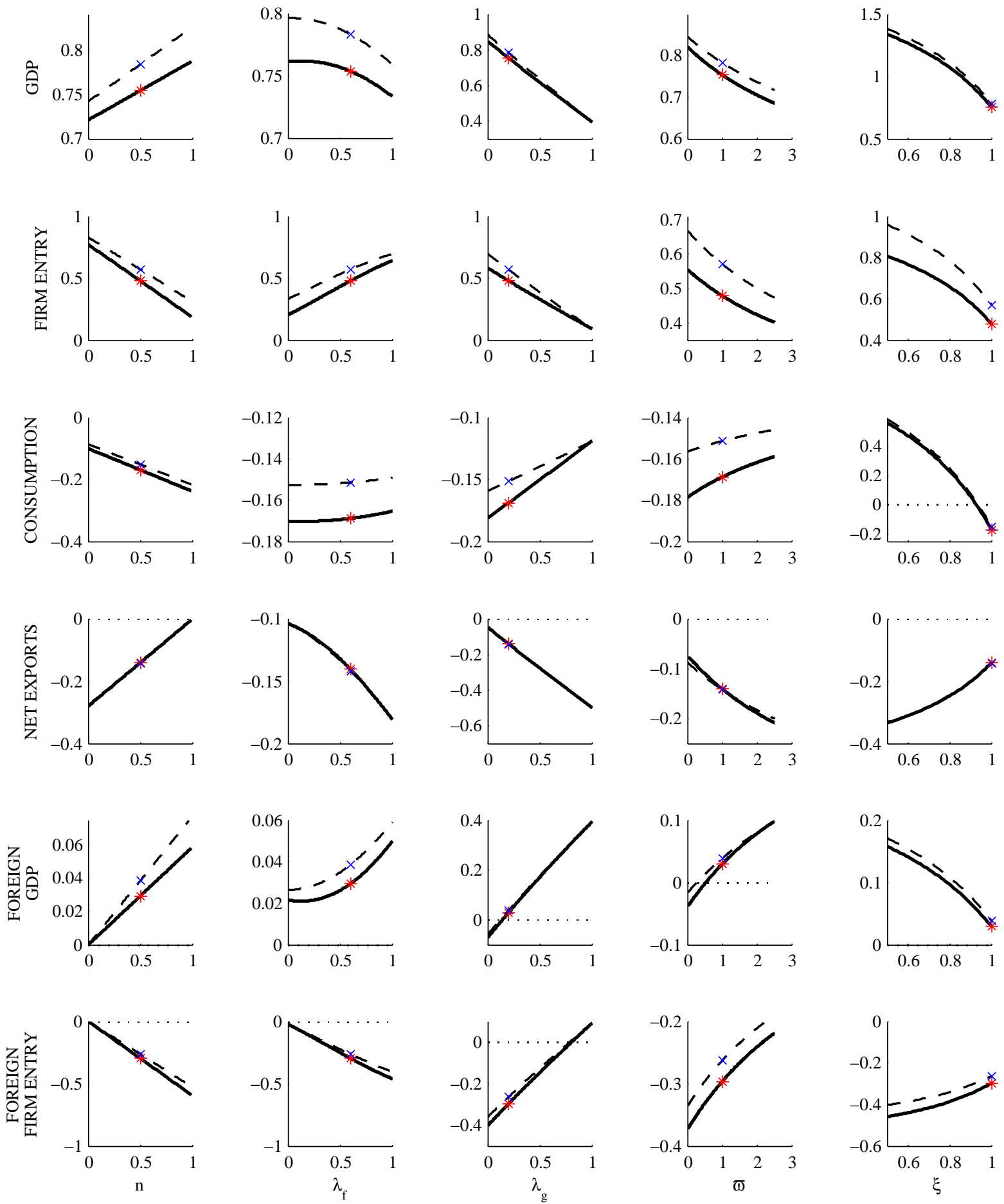

Notes: Solid lines (dashed lines) show multipliers under floating (fixed) exchange rates, * $(\mathrm{x})$ marks baseline calibration. Multipliers are computed as cumulative change in variable of interest relative to cumulative change in government spending during first 12 quarters. Net entry and foreign multipliers are expressed in elasticity form. $n$ is relative size of domestic economy, $\lambda_{f}\left(\lambda_{g}\right)$ measures degree of openness in entry costs (government spending), $\varpi$ is the trade elasticity, $(1-\xi)$ measures share of government spending in consumption composite (as explained in Section 5). 
Figure 2: - Continued.
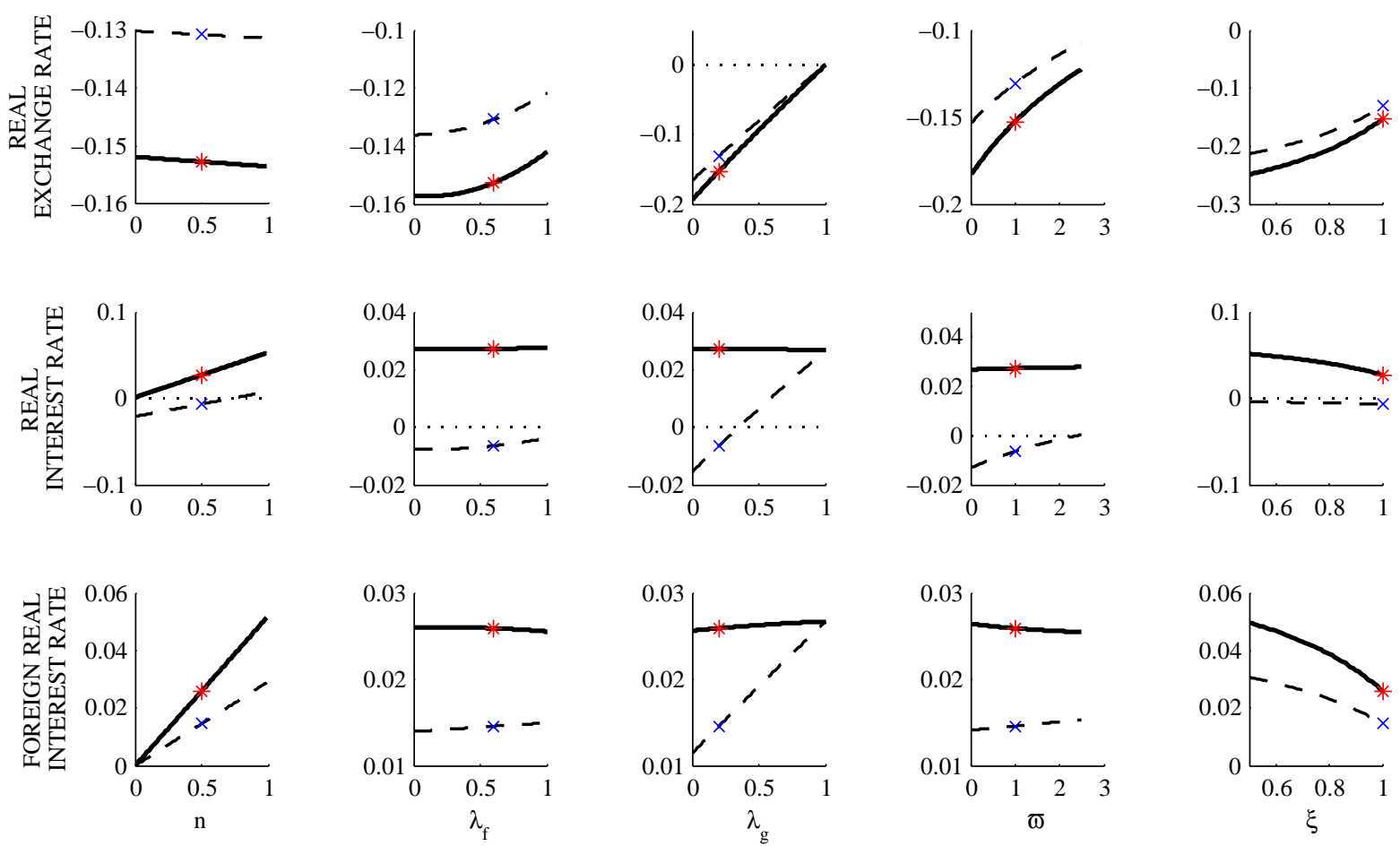

Notes: Solid lines (dashed lines) show multipliers under floating (fixed) exchange rates, $*(\mathrm{x})$ marks baseline calibration. Multipliers are computed as cumulative percentage change in variable of interest relative to cumulative percentage change in government spending during first 12 quarters. $n$ is relative size of domestic economy, $\lambda_{f}\left(\lambda_{g}\right)$ measures degree of openness in entry costs (government spending), $\varpi$ is the trade elasticity, $(1-\xi)$ measures share of government spending in consumption composite (as explained in Section 5).

Figure 3: Useful Government Spending.
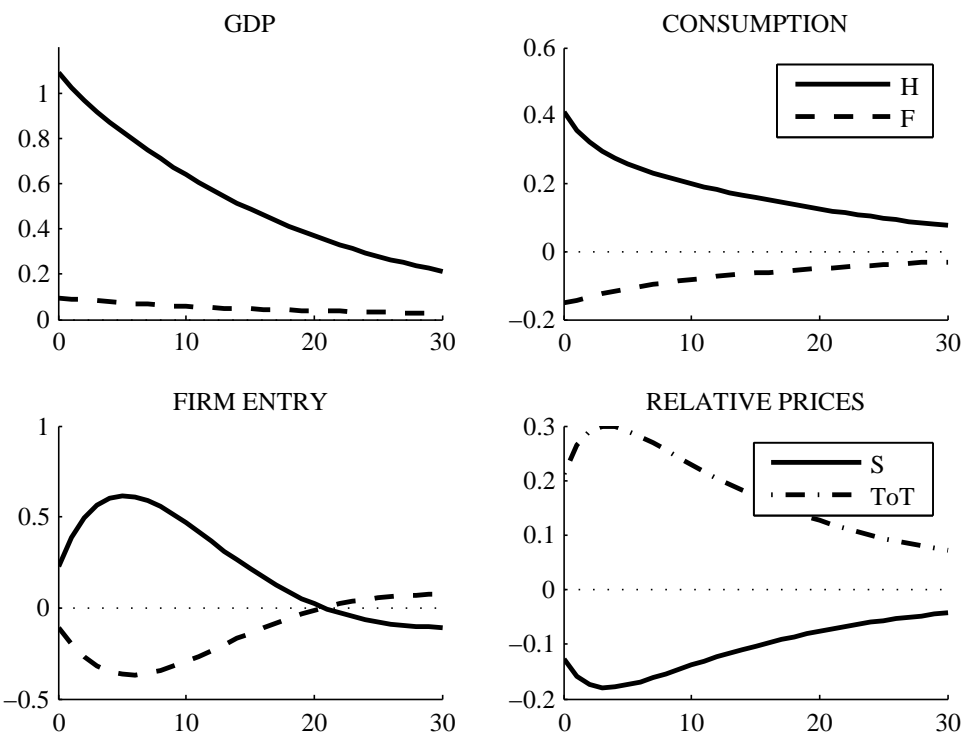

Notes: Solid lines show responses of domestic variables $(H)$, dashed lines show responses of foreign variables $(F)$. The lower right panel shows responses of the real exchange rate $S=\mathcal{E} P^{*} / P$ (solid line) and the terms of trade $T o T=P_{H} / P_{F}$ (dashed-dotted line). Responses are expressed in percentage deviations from steady state. The horizontal axes measure time in quarters. 